\title{
Spontaneous Rupture of the Stomach in the Newborn: Clinical and Experimental Evaluation
}

\author{
A. EVERETTE JAMES, JR., RICHARD M. HELLER, JR., (18) JOHN J. WHITE, JOHN A. SCHAEFER, \\ ISSAM J. SHAKER, J. ALEX HALLER, JR., AND JOHN P. DORST

\begin{abstract}
Department of Radiology and Radiological Science, Laboratory for Diagnostic Radiological Research, Division of Pediatric Radiology and Department of Surgery, Division of Pediatric Surgery, The Johns Hopkins Medical Institutions, Baltimore, Maryland, USA
\end{abstract}

\section{Extract}

Our study presents an experimental model for studying gastric rupture in the newborn. We showed that gastric rupture could be produced in eight newborn rodents and in three puppies less than 10 days old after injection of $120 \mathrm{ml}$ air at $100 \mathrm{~mm} \mathrm{Hg}$ pressure in the rodents and $175 \mathrm{ml}$ air at $240 \mathrm{~mm} \mathrm{Hg}$ pressure in the puppies. Gastric rupture occurred with animals supine and with approximately $20 \mathrm{ml}$ barium injected into the stomach. Positioning of the animal in the supine position permitted the barium to pool in the antral-pyloric region of the stomach.

\section{Speculation}

We believe that spontaneous gastric rupture occurs as a result of a "fluid-air trap." Pooling of liquid barium or food in the pylorus permits a physiologic outlet obstruction of the stomach. Our observations indicate that normal infants accumulate considerable amounts of air in the stomach while feeding. As the stomach distends reflux of air into the esophagus is impeded by an air-fluid trap at the esophageal-gastric junction. Thus, our study suggests that increased intraluminal pressure within the stomach is sufficient to cause gastric rupture in the newborn and that the fluid-air trap is an important mechaism in gastric rupture.

Spontaneous rupture of the stomach characteristically occurs in the first days of life as a linear tear high on the stomach wall. Since the original description by Siebold in 1825 , there has been a great deal of speculation and a variety of theories regarding the etiology of this catastrophic event $(3,16)$. In the some 200 cases reported in the literature, the mortality appears to be approximately $50 \%$ (14, 15).

Radiographically, stomach rupture in the neonate is characterized by massive pneumoperitoneum. The stomach often is devoid of air and rarely has an air-fluid level. The air lies superiorly and drapes over the inferiorly displaced abdominal contents, sometimes referred to as the "saddle bag" sign. Much of the large volume of intra-abdominal gas when the infant presents must be from swallowing. Whether this air is ingested before the rupture, causing it, or whether the aerophagia occurs afterwards has not been established (15). Our study was designed to investigate: (I) whether a healthy infant may have enough air in his stomach to cause rupture and account for the large volume present after rupture and, (2) to test the theory that fluid within the stomach can produce an "air trap" valve that prevents escape of swallowed air from the stomach to the small bowel or esophagus (6).

\section{MATERIALS AND METHODS}

To measure the volume of ingested air, 13 infants ( 2 weeks to 3 months of age) were studied. Gastrostomy tubes had been placed previously for therapeutic reasons. Before the tubes were removed, when the infants were taking formula orally, the gastrostomy tubes were vented to a large collecting balloon above each patient (15). The air swallowed into the stomach was readily measured with this system (Fig. 1). Because spontaneous rupture usually occurs when an infant is supine (6), these infants were fed in this position, which also prevented eructation. Initially, the infants were fed standard formula, but after two gastrostomy tubes partially obstructed, they were fed with sugar water only. Larger volumes of air were collected from this latter group.

To explore Hood's theory (6), that the antrum acts as a "fluid trap," the following experiment was performed. After intramuscular anesthesia, a thin nasogastric tube was placed in either rats', guinea pigs', or puppies' stomachs under fluoroscopic control. With the animal supine, either standard infant formula or an equivalent volume of thin $(25 \%)$ barium sulfate suspension (approximately $20 \mathrm{ml}$ in each instance) was instilled into the stomach. The animal was positioned so that the liquid pooled in the antral-pyloric region (as checked fluoroscopically in the animals given the barium suspension). A "Y" connector was placed in the proximal end of the nasogastric tube. One end of the $Y$ connector was joined with a 50-cc syringe, permitting increments of air to be int roduced; the other end was connected to a gauge that measured pressure after each injection (Fig. 2).

Eight rodents (five rats and three guinea pigs) and six puppies were used for this study. After this procedure the animals were autopsied and the stomachs examined.

\section{RESULTS}

Swallowed air was collected for $24 \mathrm{hr}$ in 11 infants and for $6 \mathrm{hr}$ in the other 2 infants. The average volume of collected air in $6 \mathrm{hr}$ was $360 \mathrm{ml}$, with a range of $150-600 \mathrm{ml}$ (Table 1).

Fluoroscopic observations during air injection showed distention of the stomach of all animals but actual rupture was not observed. Gastric rupture occurred in all eight rodents (Tables 2 and 3 ). Rupture was produced by an average of $120 \mathrm{ml}$ air at $100 \mathrm{~mm} \mathrm{Hg}$ pressure. In the puppies, stomach rupture proved to be age related. Rupture occurred in all three puppies of less than 10 days of age (1-2 days) after an average of $175 \mathrm{ml}$ air at $240 \mathrm{~mm} \mathrm{Hg}$ pressure. In puppies older than 10 days we were unable to produce gastric rupture although $1000 \mathrm{ml}$ or more was injected and pressures exceeded $400 \mathrm{~mm} \mathrm{Hg}$ (Table 4). Follow-up radiographs and physical examination showed that the air escaped from the stomach into the small bowel.

Autopsy disclosed linear tears high on the gastric wall (Fig. 3). These occurred on the anterior surface. but not along either curvature.

\section{DISCUSSION}

Spontaneous rupture of the stomach in the newborn is not uncommon. Siebold's original description of the dramatic event in 


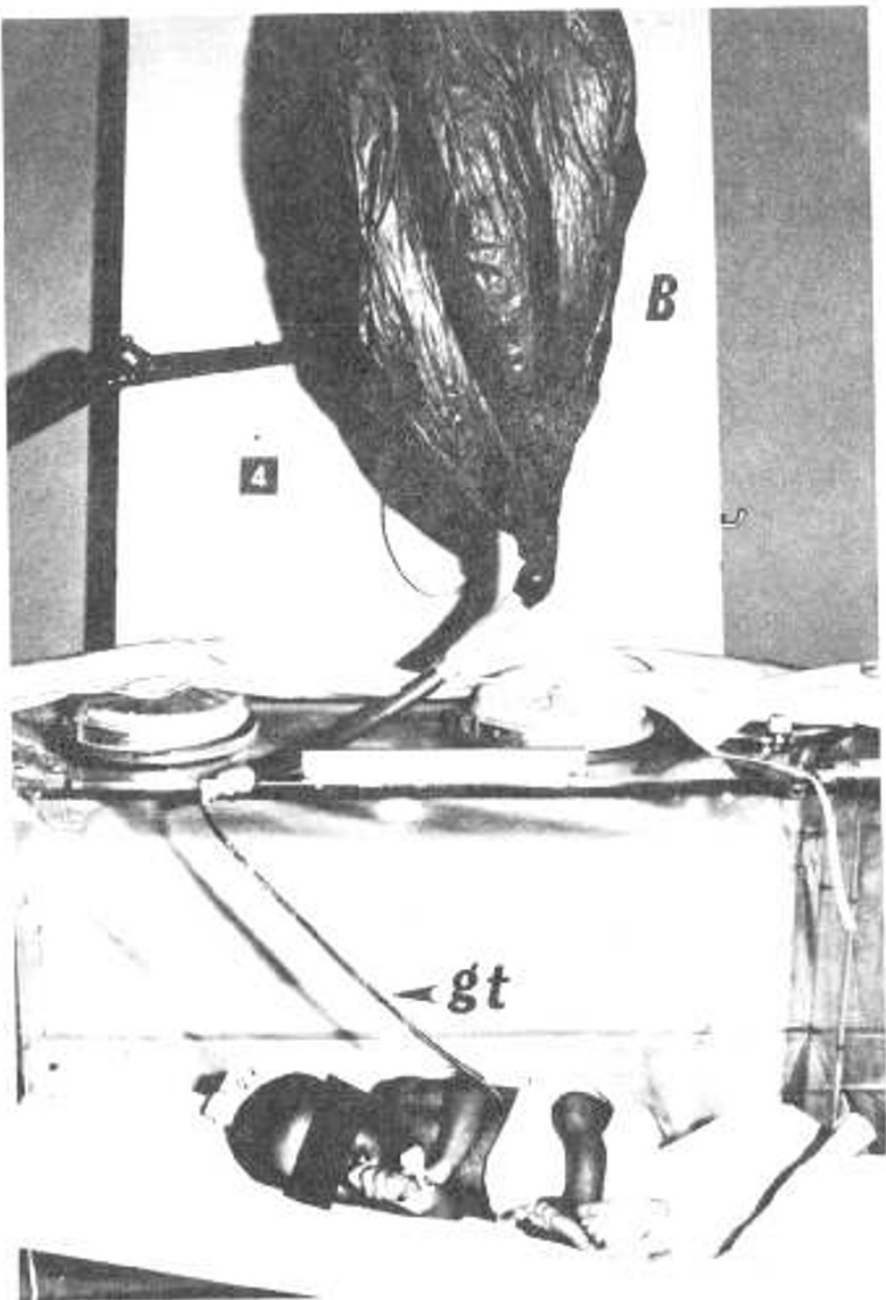

Fig. 1. System for gas collection: gastrostomy tube $(g t)$ leads to a large collection balloon $(B)$ superior to the patient.

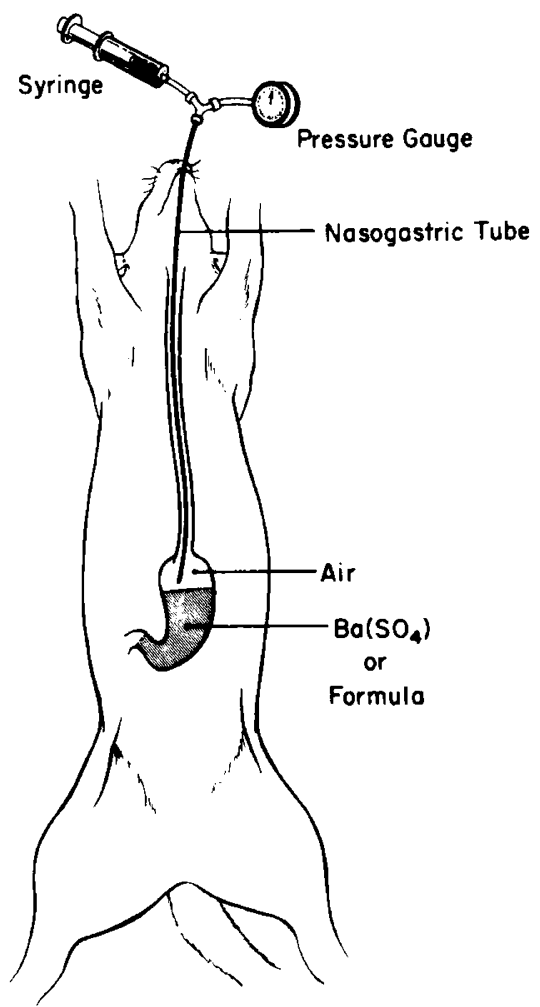

Fig. 2. Drawing of experimental model.
Table 1. Air collected in 13 infants

\begin{tabular}{cccc}
\hline Age, wk & Weight, $\mathrm{g}$ & Air volume, $\mathrm{ml}$ & $\begin{array}{c}\text { Time of } \\
\text { collection, } \mathrm{hr}\end{array}$ \\
\hline 2 & 1,800 & 800 & 6 \\
2 & 2,100 & 700 & 24 \\
2 & 2,200 & 600 & 24 \\
2 & 2,800 & $800^{1}$ & 24 \\
3 & 2,200 & 1,200 & 24 \\
3 & 3,000 & 1,400 & 24 \\
6 & 1,750 & 2,350 & 24 \\
6 & 2,500 & 1,500 & 24 \\
6 & 2,600 & 1,100 & 24 \\
8 & 2,400 & 600 & 24 \\
8 & 3,600 & $500^{1}$ & 24 \\
11 & 3,000 & 800 & 6 \\
12 & 4,000 & 1,000 & 24 \\
\hline
\end{tabular}

${ }^{1}$ Partially obstructed gastrostomy tube.

Table 2. Experimental gastric rupture in rats

\begin{tabular}{ccc}
\hline Weight, g & Air injected, $\mathrm{ml}$ & $\begin{array}{c}\text { Pressure at rupture, } \\
\mathrm{mm} \mathrm{Hg}\end{array}$ \\
\hline 175 & 90 & 40 \\
175 & 90 & 60 \\
175 & 100 & 90 \\
175 & 100 & 120 \\
175 & 100 & 90 \\
\hline
\end{tabular}

Table 3. Experimental gastric rupture in guinea pigs

\begin{tabular}{ccc}
\hline Weight, $g$ & Air injected, $\mathrm{ml}$ & $\begin{array}{c}\text { Pressure at rupture, } \\
\mathrm{mm} \mathrm{Hg}\end{array}$ \\
\hline 820 & 100 & 110 \\
870 & 180 & 140 \\
930 & 200 & 120 \\
\hline
\end{tabular}

Table 4. Experimental gastric rupture in puppies

\begin{tabular}{cccc}
\hline Age, days & Weight, g & $\begin{array}{c}\text { Air injected, } \\
\mathrm{ml}\end{array}$ & $\begin{array}{c}\text { Pressure, } \\
\mathrm{mm} \mathrm{Hg}\end{array}$ \\
\hline 10 & 610 & 180 & $280^{1}$ \\
10 & 680 & 300 & $320^{1}$ \\
10 & 720 & 150 & $120^{1}$ \\
10 & 880 & 1,200 & 400 \\
10 & 1,050 & 1,000 & 400 \\
10 & 1,680 & 1,400 & 400 \\
\hline
\end{tabular}

${ }^{1}$ Rupture.

1825 was followed by Cruveihler in 1829. Some 200 cases are documented in the world literature at the present time. At The Johns Hopkins Hospital from 1958-1972 we saw 13 infants with gastric rupture.

In 1950 Leger et al. (9) described the first successful repair of spontaneous gastric rupture; before this it was uniformly fatal. Death usually was caused by chemical or bacterial peritonitis. The gastric contents in the first $24 \mathrm{hr}$ of life are highly acid, increasing the chance of inflammation $(10,14)$.

Spontaneous gastric rupture usually occurs in the first 5 days of life (often before $48 \mathrm{hr}$ ) (2). Approximately one-third of the infants are premature, males are affected 3-12 times as often as females, and Negroes more often than Caucasians $(12,14)$. Almost always the affected infant is well until the rupture and is taken to the 


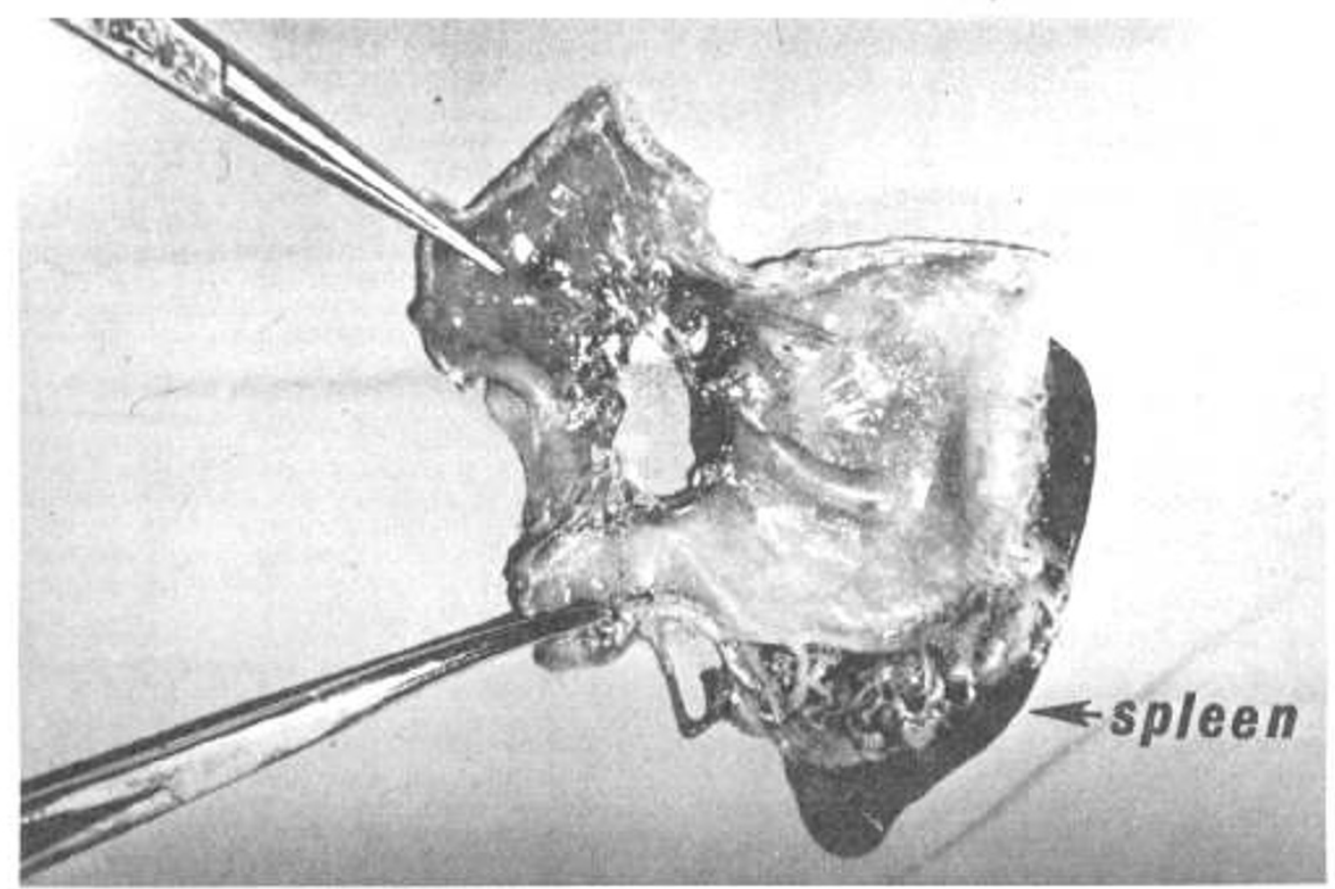

Fig. 3. Gross specimen of ruptured stomach in a puppy less than 10 days of age. Perforation high up on the gastric wall. Spleen included for orientation. Modified from Shaker et al. (15) with permission from The American Surgeon.

physician for poor feeding, anorexia and vomiting, or abdominal distention $(7,12)$. If these symptoms have gone unrecognized, the infant may be in shock or have respiratory distress because of massive pneumoperitoneum or diaphragmatic inflammation.

Physical examination shows an ill infant with a tympanic, tender abdomen. Supine radiographs show the falciform ligament. Lateral decubitus abdominal radiographs may be used to confirm the free air. Chest radiographs demonstrate elevation of the diaphragm with crowding of the pulmonary vasculature in the lower lobes and loss of the distinct vessel wall-air interface. If upright radiographs of the abdomen are made, they will show massive subdiaphragmatic gas displacing abdominal viscae inferiorly and medially. Usually no air is found in the stomach and gastric air-fluid levels are rare.

Treatment is immediate surgery with closure of the linear tear usually along the greater curvature near the cardia, and peritoneal lavage to remove spilled stomach contents $(7,14,16)$. If necessary, severe respiratory compromise can sometimes be alleviated before surgery by puncturing the upper abdomen with a large (14-gauge) needle to allow air to escape.

Considerable research and a number of mechanisms have been proposed to explain spontaneous gastric rupture in the newborn. The frequent occurrence of the linear tear near the cardia, both on the lesser and greater curvature, has led some to conclude that this is a weak part of the infant's stomach (7). Studies have suggested absence or underdevelopment of the circular musculature in the stomach. Kneiszl (8) dissected the stomachs of 15 premature and full term newborn infants and showed that there are normally gaps in the musculature in many parts of the stomach. Herbut (4) described a case of neonatal gastric rupture in which the muscularis externa was absent at the edge of the gastric tear. Subsequent experiments have shown that if the distended stomach bursts, the muscle fibers will retract and leave overhanging mucous membrane at the site of rupture; this will falsely suggest a congenital muscular defect $(11,16)$.

At the present the most widely accepted theory is that the intraluminal pressure becomes excessive $(1,3,10,15)$. Mucosa will lacerate when the transmucosal pressure gradient exceeds a critical level (1). Intraluminal gas causes radial expansion of the stomach and produces maximal tension in the mucosa in a transverse plane, tangential to the radial thrust. Disruption produces a longitudinal tear; the length of the tear corresponds to the area of the wall affected. In addition, increased intraluminal pressure produces subepithelial hemorrhage and edema. In acute hypoxemic states, blood is shunted away from the stomach by the primitive "driving reflex" which may lead to gastric wall ischemia (10). Hypoxemia did not appear to be an important factor in our patients, nor was ischemia demonstrated by the pathologic findings in our animal model.

Why such an abnormal accumulation of gas occurs has been difficult to explain. It has been proposed that this syndrome is initiated by pylorospasm (3) and gastric atony (15). Although this may well be the explanation in infants who previously received surgical or other trauma, most cases occur in previously well infants. Moreover, it does not explain why the longitudinal tears are almost always located near the cardia.

Hood (6) observed that when the infant is recumbent, the distribution of fluid in the stomach mimics the fluid-air trap of a household sink. Pooling of fluid posteriorly gives both an obstruction at the pylorus and the gastroesophageal junction. Our observations indicate that normal infants accumulate much air while feeding. The amounts exceed those proposed by some investigators to cause gastric rupture. If not permitted to escape, this ingested air can increase transmural pressure sufficiently to rupture the stomach. We have shown that fluid in the antrum temporarily prevents air entering the small bowel. As the proximal stomach distends, reflux of air into the esophagus appears impeded by a similar air-fluid trap in the cardia or by elevation of the fundus of the stomach superiorly and to the left. This latter phenomenon was observed fluoroscopically and would greatly increase the angle of entry of the esophagus into the proximal stomach impeding eructation. The pressures generated in these animals by small quantities of air suggests that an infant lying supine whose air swallowing may be increased by discomfort could readily generate sufficient transmural pressure to cause gastric rupture $(3,15)$.

The age dependence in the puppies in our experimental model is not disturbing. Eighty-four percent of spontaneous gastric perforations in human beings occur in the first 5 days of life $(2,14)$. Gastric wall development permits older infants and puppies to withstand enough intraluminal pressure to overcome the fluid "air-trap."

The roles of pylorospasm, cardiospasm, and gastric activity, and the release of epinephrine were not studied. Our experimental 
model of spontaneous gastric perforation should allow these other factors to be evaluated.

\section{SUMMARY}

Spontaneous gastric perforations usually occur in well infants during the first 5 days of life. This study shows that a well infant ingests an average of $360 \mathrm{ml}$ air in $6 \mathrm{hr}$. This amount is sufficient to cause gastric rupture if entrapped in the stomach and not allowed to escape through the esophagus or small bowel. An experimental model utilizing eight rodents and six puppies showed that fluid could prevent the movement of air distally into the small bowel. The change of angle at the gastroesophageal junction when the gastric antrum was distended with air prevented proximal reflux. Rupture was produced in the eight rodents and in the three puppies less than 10 days of age but not in the puppies older than 10 days.

\section{REFERENCES AND NOTES}

1. Bukley, G., Goldman, H., and Silen, W.: Studies on an in vivo model of acute gastric dilatation. Amer. J. Surg., /17: 193 (1969)

2. Castleton, K. B., and Hatch, F. F.: Idiopathic perforation of the stomach in the newborn. Arch. Surg., 76: 874 (1958).

3. Elders, M. J., and Hughes, E.: Rupture of the stomach: Clinical and experimental study. Lancet, 86 (3): 104 (1966).

4. Herbut, P. A.: Congenital defect in the musculature of the stomach with rupture in the newborn infant. Arch. Path., 36: 91 (1943).

5. Hodges, D. J.: Gastro-oesophageal lacerations. Med. J. Aust., 778 (1965).
6. Hood. H. H.: Clinical considerations of intestinal gas. Ann. Surg., 163: 359 (1966).

7. Inouye, W. Y., and Evans, G: Neonatal gastric perforation: A report of six cases and a review of 143 cases. Arch. Surg., 88: 471 (1964).

8. Kneiszl, F.: Some data on the etiology of gastric rupture in the newborn. Biol. Neonatal, 4: 201 (1962).

9. Leger, J. L., Richard, P. M., Leonard, C., and Piette. J.: Ulcere gastrique perfore chez un nouvra-une avec survie. Union Med. Can.. 79: 277 (1950).

10. Lloyd, J. R.: 1969. The etiology of gastrointestinal perforations in the newborn. J. Pediat. Surg., 4: 77 (1969).

II. Meyer, J. L., II: Congenital defects in the musculature of the stomach resulting in spontaneous gastric perforation in the neonatal period: A report of two cases. J. Pediat., 51: 416 (1957)

12. Parrish, R. A., Sherman, R. T., and Wilson, H.: Spontaneous rupture of the gastroenteric tract in the newborn: A report of 13 cases and description of a characteristic x-ray finding. Ann. Surg.. 159 (2): 244 (1964).

13. Plenk, H.: Z. Mikr.-Anat. Forsch., 26: 547, (1921).

4. Purcell, W. R.: Perforation of the stomach in a newborn infant. Amer. J. Dis. Child., 103: 66 (1962).

15. Shaker, I. J., Schaefer, J. A., James, A. E., and White, J. J.: Aerophagia, a mechanism for spontaneous rupture of the stomach in the newborn. Amer. Surgeon, 39 (III): 619 (1973).

16. Shaw, A., Blanc, W. A., Santulli, T. V., and Kaiser, G.: Spontaneous rupture of the stomach in the newborn: A clinical and experimental study. Surgery, $58(3)$. 561 (1965).

17. We wish to express our appreciation to the members of the Department of Radiology and Radiological Science (Dr. Martin W. Donner, Chairman). Mrs. Joseph Digel, Mr. Gary Novak, and Michael Ryan provided technical assistance.

18. Requests for reprints should be addressed to: R. M. Heller, Jr., M.D. Department of Radiology, The Johns Hopkins Medical Institutions, Baltimore, Md. 21205 (USA).

19. Accepted for publication August 14, 1975.

\title{
A Review: Relation between Invasiveness and the $\mathrm{K} 1$ Capsular Polysaccharide of Escherichia coli
}

\author{
MARK S. SCHIFFER, ELIZABETH OLIVEIRA, MARY P. GLODE, GEORGE H. MCCRACKEN, JR. \\ LARRY M. SARFF, AND JOHN B. ROBBINS(62)
}

Division of Bacterial Products, Bureau of Biologics, Bethesda, Maryland, and Department of Pediatrics, Southwestern Medical School at Dallas. Dallas, Texas, USA

Under certain conditions, Escherichia coli may invade the blood and localize in various tissues. The host factors and bacterial properties related to the penetration of $E$. coli through its usual supramucosal localization in the intestinal tract or from other sites are incompletely understood. Recently, a direct association between an invasive bacterial disease, neonatal meningitis, and a single $E$. coli structure, the $\mathrm{K} 1$ antigen, has been reported (44). Our studies of the relation to disease and characteristics of the $\mathrm{K} 1$ antigen causing neonatal meningit is in this comparatively homogeneous patient population provide some insight into the mechanisms of $E$. coli invasiveness.

The term $\mathrm{K}$ antigens of $E$. coli, first introduced by Kauffmann and Valhne (32), was intended to designate an envelope or surface structure. Most of the 100 categorized $\mathbf{K}$ antigens (International Centre for Reference and Research on Escherichia, World Health Organization) are capsular polysaccharides, similar in their overall chemical, physical, and morphologic structure to the capsular polysaccharides of highly invasive bacteria such as meningococcus, pneumococcus, and Haemophilus influenzae type b $(4,37,38)$. Originally based upon serologic reactivity, more exact biochemical and genetic information has shown that the K88 and K89 antigens are fimbriae or pili (episomal-directed proteins) that serve as attachment factors to mammalian cells (54) and that K80 antigen is a component of the somatic or $\mathrm{O}$ antigen (25).

$E$. coli $\mathrm{K}$ capsular polysaccharides are linear co- or homopolymers composed of one or several monosaccharides joined by glycosidic and/or phosphodiester bonds. A neutral $\mathrm{pH}$, they have a net negative charge because of these phosphodiester bonds or uronic acid components. The relation between capsular polysaccharides and $E$. coli invasiveness was first shown by Smith (52) and later by Kauffman (31). Surveillance data has shown that $E$. coli, isolated from extraintestinal sites, have acidic capsular polysaccharides (39). These invasive strains are found in normal intestinal tract along with a great variety of non-K antigen bearing $E$. coli. Further studies demonst rated that $\mathrm{K}$ antigens, isolated from $E$. coli that had infected renal parenchyma, had a higher molecular weight 